\title{
Imaging of acute appendicitis in children: EU versus U.S. ... or US versus CT? A European perspective
}

\author{
Herma C. Holscher • Hugo A. Heij
}

Received: 18 October 2008 /Revised: 26 November 2008 / Accepted: 10 December 2008/Published online: 3 February 2009

(C) The Author(s) 2009. This article is published with open access at Springerlink.com

\begin{abstract}
There is substantial evidence that imaging may reduce the negative appendectomy rate, also in children. However, controversy exists about the preferred method: US or CT, and the choice appears to be determined by the side of the Atlantic Ocean. This review brings forth several arguments in favour of US.
\end{abstract}

Keywords Appendix · Appendicitis · CT · Ultrasound · Children

\section{Introduction}

In making the diagnosis acute appendicitis, the clinician tries to avoid the Scylla of missing a perforation as well as the Charybdis of negative (read: unnecessary) appendectomy. The consequence of this 'safe navigation' has been that $15-25 \%$ of the appendices removed for the presumed diagnosis of acute appendicitis are normal [1]. Annually, this means that in The Netherlands with 16 million inhabitants, around 2,000 unnecessary operations are performed for suspected acute appendicitis. The diagnosis is more difficult in young children and adolescent girls and the rate of negative appendectomy is therefore higher in these categories [2].

\section{H. C. Holscher}

Department of Pediatric Radiology,

Juliana Children's Hospital/Haga Ziekenhuis,

Den Haag, The Netherlands

\section{H. A. Heij ( $\square)$}

Pediatric Surgical Center of Amsterdam,

Emma Children's Hospital AMC \& Vu University Medical Center,

P.O. Box 22660, 1100DD Amsterdam, The Netherlands

e-mail: h.a.heij@amc.uva.nl
Traditional teaching said that "when in doubt, take it out", but this attitude is more and more questioned, as it has been shown that the complication rate of negative appendectomy is similar to that of operation for simple appendicitis, namely around $11 \%$ [3]. This figure includes only the short-term complications, such as wound abscess, prolonged ileus and respiratory tract infections. Long-term complications, such as adhesive small bowel obstruction have been reported to occur in up to $5 \%$ of patients after negative appendectomy. Add to these complications, the pain, emotional upset and social disruption, and the financial cost of negative appendectomy, and it will be clear that such a procedure should be avoided. Therefore, we propose that a negative appendectomy is no longer considered as an inevitable side effect of surgical decision making, but as a complication itself $[4,5]$.

\section{How to avoid negative appendectomy?}

As outlined above, making the diagnosis of acute appendicitis solely on clinical grounds leads to a high rate of negative appendectomy. With modern imaging methods, when applied timely and if viewed critically, as an adjunct to clinical decision making, the accuracy can be improved up to $95 \%$ [6-8]. Although not all publications have been able to confirm improved accuracy, this might be due to methodological flaws, lack of experience of the imaging specialists, or poor patient selection. The diagnostic value of a test is related to the a priori chance or prevalence of the disease in the study population. Wide application of a diagnostic test such as imaging to an unselected group of patients with abdominal pain will result in a lower accuracy than when used in a group of patients selected by clinicians on the basis of history, physical findings and basic 
laboratory data [9]. Wholesale use of either CT or US without thorough examination by an experienced surgeon will not lead to improved diagnostics and reduction of the negative appendectomy rate $[10,11]$.

\section{US or CT in children with suspected appendicitis?}

Prospective studies comparing US and CT in children with suspected appendicitis are difficult to perform because of methodological and ethical arguments. Comparisons between published data are hampered by certain cultural backgrounds; in Europe, US is often performed by radiologists, whereas in the USA this is done by ultrasonographers. This may help to explain the different values ascribed to these methods. Furthermore, body-mass-index of children in the USA is significantly higher than in Europe $[12,13]$.

Although the diagnostic accuracy of $\mathrm{CT}$ is reported to be higher than that of US, particularly in adults, it is debatable whether $\mathrm{CT}$ is able to reduce the negative appendectomy rate in children $[14,15]$.

What are the arguments in favour of US? There is the concern about the long-term effects of radiation from CT in children. Literature reports about the increased risk of cancer induction suggest that the dangers of CT are severely underestimated in this respect [16]. Primum nil nocere (first do no harm) dictates us to refrain from potentially harmful procedures if other tests are available. Besides the radiation risk, $\mathrm{CT}$ is also less desirable in children because of their lack of abdominal fat. Fat stranding is difficult to recognize and the appendix may be difficult to distinguish from surrounding bowel due to the absence of body fat [17]. Furthermore, CT, in contrast to US, is more expensive, more invasive with the use of oral, intravenous, or rectal contrast medium, requires sedation in some children and brings additional risks with contrast agents [18]. CT reports are operator dependent, just like US. Publication bias may obscure this, as the studies by experienced and dedicated CT specialists are more likely to be published [19].

US, if performed by experienced and dedicated radiologists, may achieve a diagnostic accuracy that is as good as CT. The advantages of US in children are well recognized: the relatively thin abdominal wall and the absence of fat make these patients more suited for US than for CT, which requires fat tissue to distinguish the intra-abdominal organs [20-22].

The normal appendix can be seen in $82 \%$ of asymptomatic children [23]. If the normal appendix can be visualised with US, appendicitis can be safely ruled out. US signs of appendicitis are a non-compressible appendix with a diameter of $6 \mathrm{~mm}$ or more, with or without the presence of an appendicolith. Care should be taken in patients with cystic fibrosis as in these patients the appendix is often enlarged ( $>8 \mathrm{~mm}$ in diameter) due to mucoid impaction, without appendicitis [24].

Secondary signs such as increased echogenicity of the surrounding area of the appendix suggesting inflammation of mesenteric fat, local fluid collections suggesting an appendicular abscess, or local dilatation of the thin bowel without peristalsis indicating focal peritonitis, might be present. In these cases the diagnosis of appendicitis can be safely made [25].

What about the cases in which the appendix cannot be seen with US - the equivocal cases? If secondary signs of appendicitis are present, without visualisation of the appendix, the diagnosis of appendicitis is very likely. A pitfall might be primary bacterial peritonitis, in which secondary signs may be seen without appendicitis. If no secondary signs are seen, i.e. the US examination is normal or an alternative diagnosis is seen, appendicitis is very unlikely.

In equivocal cases a short period of observation with repeated examination by the same clinician has not been shown to increase the risk of perforation in patients without generalised peritonitis. If, on the other hand, the abdominal signs and symptoms are severe, surgical intervention will be indicated. In those circumstances, diagnostic laparoscopy may be the best option, although this requires general anaesthesia. If the clinical judgement is that a condition may be present that does not require acute surgical intervention, e.g. pancreatitis or Crohn disease, CT should be considered [26].

\section{Conclusion}

Appendectomy should not be undertaken without imaging to confirm the clinical suspicion. The choice between US and $\mathrm{CT}$ will have to be made on the basis of available expertise in combination with common sense. The radiation risk of $\mathrm{CT}$ in children is an obstacle of sufficient size to make us prefer US as the imaging study of first choice, particularly as the diagnostic yield of US is comparable to CT.

Open Access This article is distributed under the terms of the Creative Commons Attribution Noncommercial License which permits any noncommercial use, distribution, and reproduction in any medium, provided the original author(s) and source are credited.

\section{References}

1. Bakker OJ, van den Broek FJ, Puylaert JB et al (In press) Increased use of non-structural preoperative imaging did not decrease the negative appendectomy rate 
2. Klein MD, Rabbani AB, Rood KD et al (2001) Three quantitative approaches to the diagnosis of abdominal pain in children: practical applications of decision theory. J Pediatr Surg 36:1375-1380

3. Margenthaler JA, Longo WE, Virgo KS et al (2003) Risk factors for adverse outcome after surgical treatment of appendicitis in adults. Ann Surg 238:59-66

4. Colson M, Skinner KA, Dunnington G (1997) High negative appendectomy rates are no longer acceptable. Am J Surg 174:723-726

5. Jones K (2004) Are negative appendectomies still acceptable? Am J Surg 188:748-754

6. Doria AS, Moineddin R, Kellenberger CJ et al (2006) US or CT for diagnosis of appendicitis in children and adults? A metaanalysis. Radiology 241:83-94

7. Terasawa T, Blackmore CC, Bent S et al (2004) Systematic review: computed tomography and ultrasonography to detect acute appendicitis in adults and adolescents. Ann Intern Med 141: 537-546

8. Weston AR, Jackson TJ, Blamey S (2005) Diagnosis of appendicitis in adults by ultrasonography or computed tomography: a systematic review and meta-analysis. Int J Technol Assess Health Care 21:368-379

9. Anderson RE (2004) Meta-analysis of the clinical and laboratory diagnosis of appendicitis. Br J Surg 91:28-37

10. Garcia Pena BM, Taylor GA, Fishman SJ et al (2002) Effect of an imaging protocol on clinical outcomes among pediatric patients with appendicitis. Pediatrics 110:1088-1093

11. Heij HA, Offringa M (2004) Effect of an imaging protocol on clinical outcomes among pediatric patients with appendicitis. Pediatrics 113:626

12. Vincent SD, Pangrazi RP, Raustrop A et al (2003) Activity levels and body mass index of children in the United States, Sweden and Australia. Med Sci Sports Exerc 35:1367-1373

13. Mathus-Vliegen EM (1998) Overweight. I. Prevalence and trends. Ned Tijdschr Geneeskd 142:1982-1987
14. Stephen AE, Segev KL, Ryan DP et al (2003) The diagnosis of appendicitis in a pediatric population: to CT or not to CT. J Pediatr Surg 38:367-371

15. Martin AE (2004) CT scans may not reduce the negative appendectomy rate in children. J Pediatr Surg 39:886-890

16. Brenner D, Ellison C, Hall E et al (2001) Estimated risks of radiationinduced fatal cancer from pediatric CT. AJR 176:289-296

17. Friedland JA, Siegel MJ (1997) CT appearance of acute appendicitis in childhood. AJR 168:439-442

18. Kwok MY, Kim MK, Gorelick MH (2004) Evidence-based approach to the diagnosis of appendicitis in children. Pediatr Emerg Care 20:690-698

19. in 't Hof KH, van Lankeren W, Krestin GP et al (2004) Surgical validation of unenhanced helical computed tomography in acute appendicitis. Br J Surg 91:1641-1645

20. Hahn HB, Hoepner FU, Kalle T et al (1998) Ultrasonography in suspected acute appendicitis in children: 7 years experience. Pediatr Radiol 28:147-151

21. Schulte B, Beyer D, Kaiser C et al (1998) Ultrasonography in suspecte acute appendicitis in childhood - report of 1285 cases. Eur J Ultrasound 8:177-182

22. van den Ende ED, Boellaard WP, Allema JH et al (2003) Diagnostic surplus value of echography in children with acute abdominal pain. Ned Tijdschr Geneeskd 147:1174-1177

23. Wiersma F, Srámek A, Holscher HC (2005) US features of the normal appendix and surrounding area in children. Radiology 235:1018-1022

24. Lardenoye SW, Puylaert JB, Smit MJ et al (2004) Appendix in children with cystic fibrosis: US features. Radiology 232:187-189

25. Wiersma F, Torenvliet BR, Bloem JL et al (2008) US examination of the appendix in children with suspecte appendicitis: the additional value of secondary signs. Eur Radiol Sep 25, Epub ahead of print

26. Morrow SE, Newman KD (2007) Current management of appendicitis. Semin Pediatr Surg 16:34-40 